\title{
薬物問題の現状と薬物鑑定
}

\author{
阿久津 守
}

\section{Current Status of Drug Problems and Drug Analysis}

\author{
Mamoru Akutsu \\ Narcotics Control Department, Kanto-Shin'etsu Regional Bureau of Health and Welfare, Ministry of Health, \\ Labour and Welfare; 1-2-1 Kudan-Minami, Chiyoda-ku, Tokyo 102-8309, Japan.
}

(Received July 30, 2018)

\begin{abstract}
The number of persons arrested in Japan for drug-related offenses in 2016 increased from the previous year. Especially, cannabis offenses have increased since 2014, with more than 2000 persons arrested in 2015. As a feature of the year 2017, we analyzed many cannabis concentrates, called "Cannabis wax", in the process of analyzing cannabis in the Narcotics Control Department. "Cannabis wax" refers to concentrates of the hallucinogenic component of cannabis, tetrahydrocannabinol (THC). Increasingly, cannabis wax containing 50 times higher THC than general dry cannabis has been confiscated. More than 2300 compounds are currently regulated as new psychoactive substances in Japan. In a recent trend, there is an increasing number of cases in which a wide range of regulated substances have been seized and confiscated, ranging from those that have been abused for a long time, to those that are newly regulated. Many structural isomers are present among these, and we are constantly developing techniques for the rapid and accurate analysis of these compounds.
\end{abstract}

Key words — cannabis; new psychoactive substance; stimulant

\section{1. はじめに}

わが国における 2016 年の薬物事犯による検挙人 員は，13841人（指定薬物事犯を除く）で，このう ち覚醒剤での検挙者は, 10607 人であり, 依然とし て 1 万人を超える高い水準で推移している，覚醒剤 の押収量については，大量密輸事件の検挙が相つぎ, 1999 年につぐ過去 2 番目を記録するなど，国内に おける根強い薬物需要の存在が窺われ, 深刻な状況 にあると言える.11)また，減少傾向にあった大麻事 犯は 2014 年から増加に転じ, 2016 年の検挙人員は 2722 名と 2 年連続で 2000 名を超えており，特に若 年層への拡大が懸念されるところである（Fig. 1). 2) 社会問題化していた危険ドラッグ事犯につい ては，2014 年 7 月に「危険ドラッグの乱用の根絶 のための緊急対策」が策定され，政府全体で様々な 対策を講じた結果，2015 年 7 月には危険ドラッグ

厚生労働省関東信越厚生局麻薬取締部（T102-8309 東 京都千代田区九段南 1-2-1)

e-mail: akutsu-mamoru@mhlw.go.jp

本総説は, 日本薬学会第 138 年会シンポジウム S45 で 発表した内容を中心に記述したものである.
販売店が全滅した。しかし，その後も危険ドラッグ の販売手法は店舗型からインターネット販売やデリ バリー販売へ移行するなど，その流通ルートはより 巧妙化・潜在化しており，引き続き十分な警戒が必 要である.

\section{2. 薬物問題の現状と鑑定事例}

2-1. 大麻乱用の拡大 大麻事犯の検挙人員の うち 10 代・ 20 代の割合は 4 割強を占め, 覚醒剂等 他の薬物と比較して，若年層の比率が高いことが特 徵であるが, この背景として, 大麻は無害であると いつた誤つた情報がインターネット上に溢れてお り，安易に大麻の乱用へ向かってしまうことが挙げ られる。また，2015 年以降，危険ドラッグの検挙 人員は減少傾向を見せ始めているが，大麻事犯の増 加は，これと負の相関関係にある。つまり，元々大 麻を乱用していた者が，一時的に危険ドラッグへ移 行したものの，取締りの強化により，大麻へ回帰し たと考えられている.さらに大麻事犯の現況とし て, 倉庫等を借り切り, 大規模に大麻栽培を敢行し ている事例が頻発しており，今後もますます大規模 栽培化が進んでいくことが懸念される．また，最近 


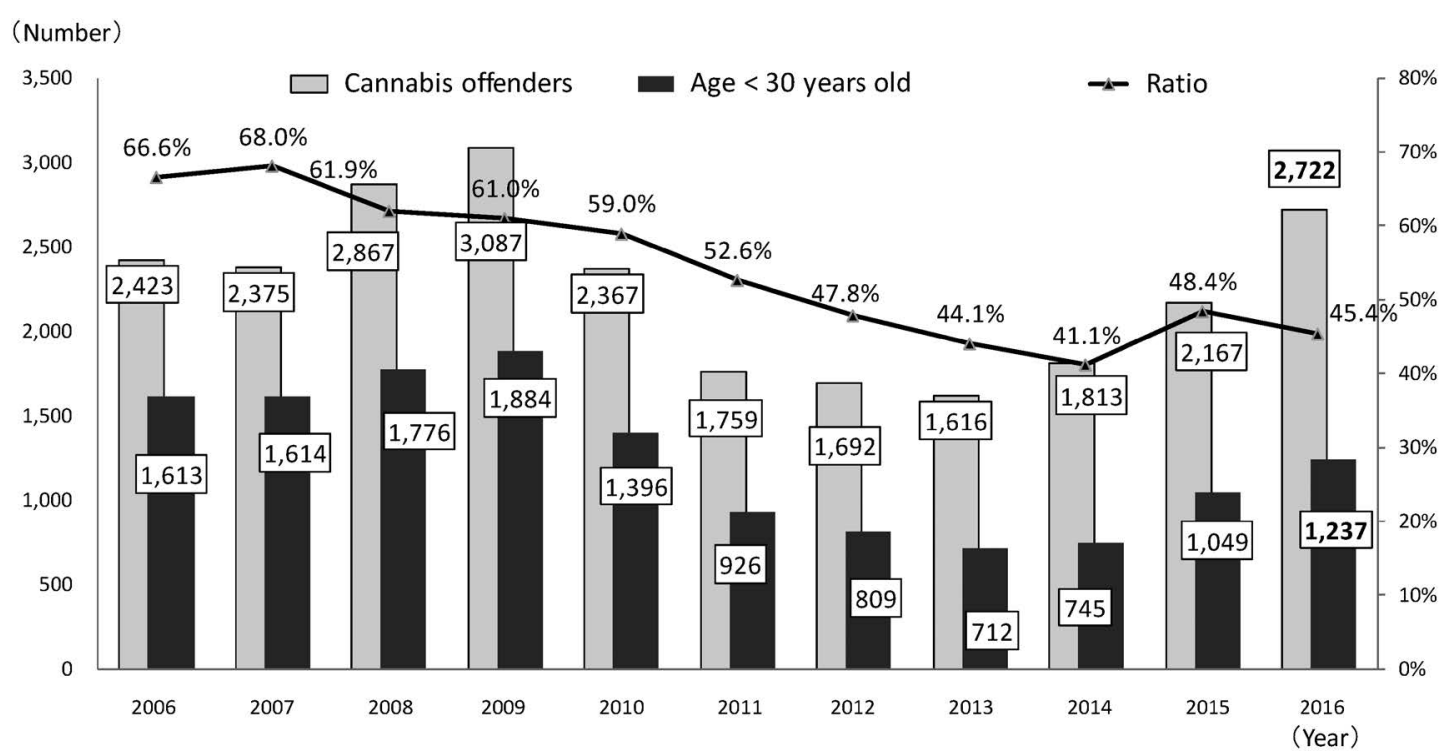

Fig. 1. Number of Persons Arrested for Cannabis-related Crimes by Year

押収される大麻は，植物片や大麻樹脂以外にも，大 麻成分を濃縮した粘性の物質や食品の形状をしたも の等，様々な形状のものが流通していることから も，更なる乱用の拡大が予想される。このような状 況下，関東信越厚生局麻薬取締部では室内で大規模 に栽培される大麻事犯に係る鑑定などを行ってきた が，特に 2017 年では，「大麻ワックス」などと呼ば れる大麻濃縮物に係る定量試験を含む鑑定を数多く 実施した。なお大麻の幻覚成分であるテトラヒドロ カンナビノール（tetrahydrocannabinol; THC）な どのカンナビノイドの定量試験については，国連薬 物犯罪事務所が推奨する大麻成分定量法に準じて試 験を実施している. ${ }^{3)} 2016$ 年から 2017 年において 定量試験を実施した大麻濃縮物は合計 132 検体であ り，そのうち黄色粘性物質である大麻ワックスは, 47 検体であった（Table 1)。大麻ワックスは，ブ タンガスなどで抽出を行うことにより THC の濃度 を高めたもので，一般的な乾燥大麻の THC 濃度が 10\%以下であるのに対し, ${ }^{4)} \mathrm{THC}$ 濃度の平均值は約 $50 \%$ と高濃度であった。特に最近押収されている 「電子たばこカートリッジ入りの大麻濃縮液」（Fig. 2）については，(1)小型であるため発見が困難，(2) 臭いも少なく，大麻を吸煙しているとは思われない， (3)平均 $60 \%$ と高濃度の THC を含有しているなどの 理由から看過できない危険な薬物であることから, 取締りが強化されているところである. 一般に大麻 の鑑定は，形態学的検査と理化学的検査を並行して
Table 1. THC Concentrations of Cannabis Concentrates Seized between 2016 and 2017

\begin{tabular}{lccc}
\hline \hline Cannabis concentrates & $n$ & $\begin{array}{c}\text { THC concentration } \\
(\%) \\
\text { Mean } \pm \text { S.D. }\end{array}$ & $\begin{array}{c}\text { Range } \\
(\%)\end{array}$ \\
\hline Cannabis wax & & \\
Yellow sticky substances & 47 & $48.87 \pm 12.93$ & $16.30-67.90$ \\
Electronic cigarettee for cannabis & 74 & $59.26 \pm 4.23$ & $48.19-70.74$ \\
Yellow liquids & 5 & $18.77 \pm 2.59$ & $15.06-21.87$ \\
Black liquids & & & \\
Others & 6 & $41.83 \pm 6.78$ & $35.80-49.07$ \\
Black sticky substances & 6 & &
\end{tabular}



Fig. 2. Electronic Cigarette for Cannabis 
<smiles>CC1NCCOC1c1ccc(F)cc1C1OCCNC1C</smiles>

Fig. 3. Chemical Structures of Fluorophenmetrazine (FPM)

行うが, 5,6 これら大麻濃縮物については, 本来の植 物形態から逸脱していることが多く, 形態学的検查 の実施が困難な場合がある.この植物形態学的検査 を補強する意味合いから，大麻の香気成分であるセ スキテルペノイドの一部を確認することで植物由来 である確認を行うことや, 7) 理化学試験においては 複数のカンナビノイドを確認することなどで，大麻 濃縮物の鑑定を実施しているところである.

2-2. 危険ドラッグ（指定薬物）の現況深刻 化する危険ドラッグ問題に対処するため，厚生労働 省は 2006 年に薬事法を改正し，興奮等の作用を有 する蓋然性が高く，保健衛生上の危害が発生する恐 れがある薬物や植物を厚生労働大臣が「指定薬物」 として, 医療等の用途以外の製造，輸入，販売等を
禁止することとなつた。 ${ }^{8)}$ 指定薬物については 2018 年 6 月現在 2373 化合物が規制されているが，最近 の傾向としては，2014 年 6 月に規制されたにもか

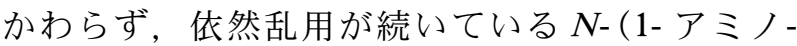
3-メチル-1-オキソブタン-2-イル)-1-(5-フルオロペ ンチル) - $1 H$-インダゾール-3-カルボキサミド $[N-(1-$ amino-3-methyl-1-oxobutan-2-yl)-1- (5-fluoropentyl) - $1 H$-indazole-3-carboxamide; 5-fluoro-AB-PINACA] などの合成カンナビノイドから 2017 年 2 月に規制 された 2-(2-フルオロフェニル)-3-メチルモルフォ リン [ 2- ( 2-fluorophenyl ) -3-methylmorpholine; 2-FPM] まで，幅広く押収されるケースがある. 9,10)

2-3. 鑑定事例 2-FPM には置換基の位置が異 なる 2 種類の異性体, 2-(3-フルオロフェニル)-3-メ チルモルフォリン [2-(3-fluorophenyl)-3-methylmorpholine; 3-FPM] 及び 2-(4-フルオロフェニル) 3-メチルモルフォリン [2- (4-fluorophenyl) -3methylmorpholine; 4-FPM] が存在し，すべて指定 薬物として指定されている（Fig. 3)。これらの異 性体について，未処理のまま GC-MS を行うと,

3-FPM と 4-FPM は分離せず [Fig. 4(a)], 各異性
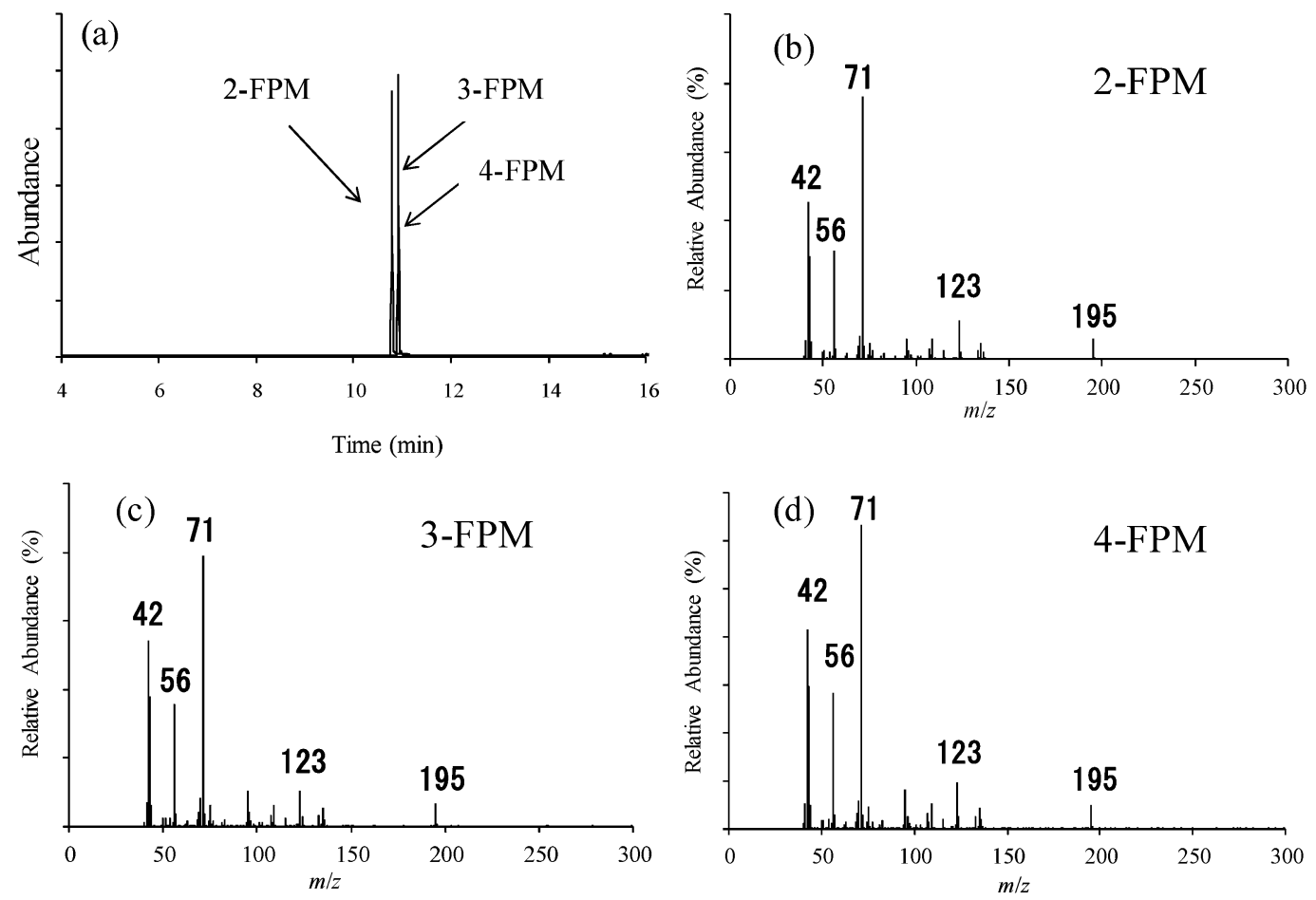

Fig. 4. Total Ion Current Chromatograms Obtained from Authentic Standards of 2-FPM, 3-FPM, and 4-FPM (a) and Mass Spectra of 2-FPM (b), 3-FPM (c), and 4-FPM (d)

GC-MS conditions: column, DB- $5 \mathrm{~ms}(30 \mathrm{~m} \times 0.25 \mathrm{~mm}$ i.d., $0.25 \mu \mathrm{m})$; carrier gas, He; flow rate, $1.1 \mathrm{~mL} / \mathrm{min}$; injector temperature, $250^{\circ} \mathrm{C}$; oven temperature program, $60^{\circ} \mathrm{C}(1 \mathrm{~min}$ hold $)-10^{\circ} \mathrm{C} / \mathrm{min}-300^{\circ} \mathrm{C}$; ionization, electron ionization; ionization energy, $70 \mathrm{eV}$; scan range, $m / z 40-500$; injection volume, $1 \mu \mathrm{L}$. 



Fig. 5. Total Ion Current Chromatograms Obtained from Authentic Standards of 2-FPM-HFB, 3-FPM-HFB, and 4-FPM-HFB (a) and Mass Spectra of 2-FPM-HFB (b), 3-FPM-HFB (c), and 4-FPM-HFB (d)

GC-MS oven temperature program: $60^{\circ} \mathrm{C}(1 \mathrm{~min}$ hold $)-10^{\circ} \mathrm{C} / \mathrm{min}-150^{\circ} \mathrm{C}(4 \mathrm{~min}$ hold $)-20^{\circ} \mathrm{C} / \mathrm{min}-300^{\circ} \mathrm{C}(5 \mathrm{~min}$ hold $)$.

体のマススペクトルに差異はないことから [Figs. 4 (b) - (d)], 当該異性体の同定は困難であった。 そ こで, McLaughlin らの報告を参考に, 11) 同異性体 のヘプタフルオロブチル (HFB) 誘導体化を行つ たところ，各異性体を分離することが可能となった (Fig. 5)。このような類似の構造を持つ異性体分析 において，前述のように分離が困難な場合もある が，同誘導体化の応用は有用であると考えている. 2000 種を超える指定薬物を迅速かつ正確に分析を 行うため, 本事例のように各化合物に適応した手法 を絶えず開発しているところである.

\section{3. おわりに}

薬物事犯による検挙人員は，覚醒剂事犯を中心と して 1 万人を超える高い水準で推移しているが，こ のほか，大麻や指定薬物事犯など多種多岐にわた り，薬物乱用は依然憂慮すべき問題であり，予断を 許さない状況にある。.大麻取締法では一属一種の大 麻草の製品を対象にしているにもかかわらず，乾燥 大麻，大麻樹脂，大麻ワックスなどの大麻濃縮物等 種類も多く，これらの鑑定は通常の分析で対応でき なくなっているものも存在する．また 2000 種を超 える指定薬物では，液体や固体はもちろん，亜酸化 窒素のような気体のものまで存在する。現在の薬物
鑑定では分析法の開発に留まらず，現在乱用されて いる薬物の傾向などの情報収集を行う必要がある. 薬物乱用は今後益々多種多岐に広がる傾向にある が，これら対策のため，あらゆる施策を講じる必要 があると考えられる。

謝辞本試験に使用した 2-FPM，3-FPM 及び 4-FPM については，国立医薬品食品衛生研究所よ り提供を受けたものを使用した。

利益相反＼cjkstart開示すべき利益相反はない.

\section{REFERENCES}

1) The Ministry of Health, Labour and Welfare, "The General Situation of Administrative Measures against Narcotics and Stimulants," Preamble, 2017.

2) The Ministry of Health, Labour and Welfare: 〈http://www.mhlw.go.jp/stf/seisakunitsuite/ bunya/0000193406.html $\rangle$, cited 1 June, 2018.

3) United Nations Office on Drugs and Crime (UNODC), "Recommended methods for the identification and analysis of cannabis and cannabis products,"' 2009. 
4) Tsumura Y., Aoki R., Tokieda Y., Akutsu M., Kawase Y., Kataoka T., Takagi T., Mizuno T., Fukada M., Fujii H., Kurahashi K., Forensic Sci. Int., 221, 77-83 (2012).

5) Kuwayama K., Tsujikawa K., Kanamori T., Iwata Y. T., Inoue H., Jpn. J. Forensic Sci. Tech., 18, 135-141 (2013).

6) Kuwayama K., Tsujikawa K., Kanamori T., Iwata Y. T., Inoue H., Jpn. J. Forensic Sci. Tech., 18, 143-153 (2013).

7) Iwata Y. T., Kanamori T., Miyaguchi H., Tsujikawa K., Kuwayama K., Yamamuro T., Segawa H., Inoue H., Rep. Natl. Res. Inst.
Police Sci., 66, 1-10 (2017).

8) Hanajiri R. K., Uchiyama N., Kawamura M., Ogata J., Goda Y., Yakugaku Zasshi, 133, 3140 (2013).

9) Akutsu M., Sugie K., Saito K., Forensic Toxicol., 35, 94-103 (2017).

10) Akutsu M., Sugie K., Saito K., Bunseki Kagaku, 66, 477-486 (2017).

11) McLaughlin G., Morris N., Kavanagh P. V., Dowling G., Power J. D., Twamley B., O'Brien J., Talbot B., Sitte H. H., Brandt S. D., Drug Test. Anal., 9, 369-377 (2017). 